\title{
A computational study of anionic alkoxide-allene and amide- allene cyclizations
}

\author{
Florimond Cumine ${ }^{[a]}$, Allan Young ${ }^{[a]}$, Hans-Ulrich Reissig ${ }^{[b]}$, Tell Tuttle ${ }^{*[a]}$ and John A. Murphy ${ }^{*[a]}$
}

\begin{abstract}
Computational studies have been performed on potassium alkoxide-allenes, as well as potassium and lithium amidoallenes to probe the mechanism of their cyclizations to dihydrofurans and to 2,5-dihydropyrroles. A long-standing proposal envisaged electron transfer from dimsyl anions (formed by deprotonation of the solvent DMSO) but this pathway shows an exceptionally high kinetic barrier, while direct 5-endo-trig cyclization of the alkoxides and amides is much more easily achievable. The energy profiles for 4exo-trig cyclizations onto the allenes are also explored, and the preferred formation of the observed 5 -membered products is rationalized.
\end{abstract}

\section{Introduction}

Metallated alkoxyallenes have been widely used as building blocks for the synthesis of functionalized heterocycles. ${ }^{[1]}$ Their formation by deprotonation of readily available alkoxyallenes using $n$-butyllithium or other bases ${ }^{[2]}$ followed by reaction with electrophiles provides primary adducts that are transformed into subsequent products. Carbonyl compounds afford intermediates such as allenyl alkoxide 1, (Scheme 1) which can cyclize to afford dihydrofurans 3 . Anionic alkoxide-allene cyclizations have now been investigated, ${ }^{[3]}$ for which two different pathways have previously been proposed: (A) the direct intramolecular attack of the alkoxide oxygen 1 on the terminus of the allene, would appear to be disfavored by Baldwin's rules. ${ }^{[4]}$ However, despite a vast amount of validation of these rules over recent decades, cyclic transition states involving allenes have been relatively unstudied. ${ }^{[4,5]}$ (B) The other longstanding mechanistic proposal, put forward by Magnus et al., would involve an electron transfer from the dimsyl anion to the allene unit of 4 , to afford allene radical anion 5 and dimsyl radical $\mathbf{6}$. This is followed by hydrogen abstraction from the hydroxyl group to re-form DMSO and a diradical-anion 7. Radical recombination would then lead to cyclization to afford the anion $\mathbf{2}$ that is finally protonated to provide dihydrofuran $3 .^{[3 c]}$ Anionic cyclizations of related allenyl amines to form 2,5-dihydropyrroles have also been investigated, employing the same synthetic strategy as for the synthesis of 2,5-dihydrofurans. ${ }^{[6]}$ We now report the energies involved in such

[a] F. Cumine, A. Young, Dr. T. Tuttle* and Prof. Dr. J. A. Murphy* Department of Pure and Applied Chemistry

University of Strathclyde

295 Cathedral Street, Glasgow G1 1XL, United Kingdom

E-mail: t.tuttle@strath.ac.uk; john.murphy@strath.ac.uk www.johnmurphygroup.com

[b] Prof. Dr. H.-U. Reissig

Institut für Chemie und Biochemie

Freie Universität Berlin

Takustr. 3

14195 Berlin, Germany

Supporting information for this article is given via a link at the end of the document. cyclizations of alkoxide-allenes and amide-allenes via an anionic process, by computationally modelling these cyclizations.

\section{Computational Details}

Density Functional Theory was used for the geometry optimisations of all reactants, transition states, intermediates and products. The final optimised geometries were characterised as minima or transition states by performing frequency calculations, which also enabled calculation of the zero-point energies (ZPE), enthalpies $(H)$, entropies $(S)$ and Gibbs free energies (G) at 298K. Geometry optimisations and frequency calculations were performed using the Gaussian 09 software package,$^{[7]}$ using the M06-2X functional ${ }^{[8]}$ and 6$31++G(d, p)$ basis set. ${ }^{[9]}$ Implicit solvation was modelled using the Conductor-Like Polarizable Continuum Model (CPCM) with the associated parameters of DMSO or THF as the solvent. ${ }^{[10]}$

(A) Anionic process:

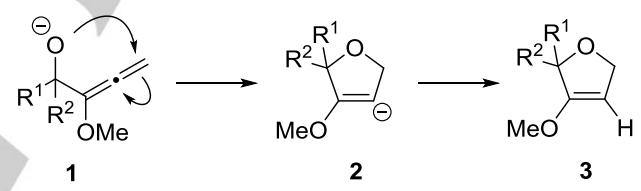

(B) Electron transfer process:

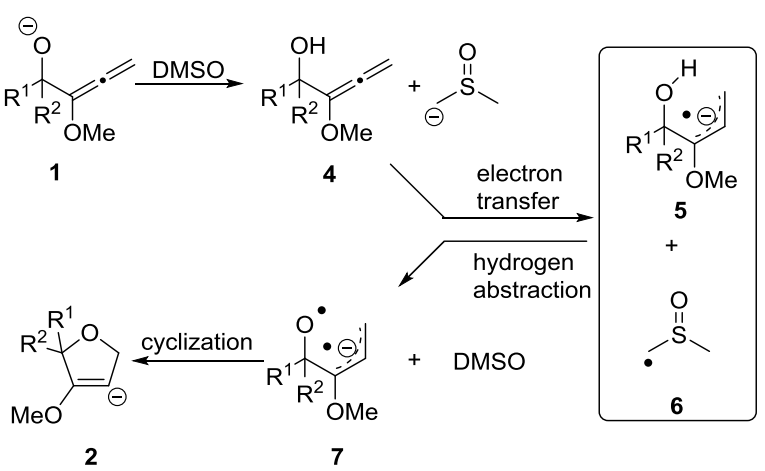

Scheme 1. Cyclization of alkoxide 1 to dihydrofuran 3 via anionic $(A)$ and electron transfer $(B)$ processes.

\section{Results and Discussion}

Our attention first focused on the cyclization of potassium alkoxide-allenes into 2,5-dihydrofurans in DMSO. The possibility of an electron transfer process from the dimsyl anion to model allene 8 was investigated utilising Marcus Theory, specifically using the Nelsen 4 point method (Scheme 2). ${ }^{[11]}$ using CPCM model parameters for DMSO. The energy barrier found (52.3 
$\mathrm{kcal} / \mathrm{mol}$ ) is too high for this reaction to be feasible. In addition, the reaction is significantly endergonic $(52.2 \mathrm{kcal} / \mathrm{mol})$. Even higher energies were found when the potassium cation was included in the optimization by using the dimsyl potassium salt 10 as an electron donor.

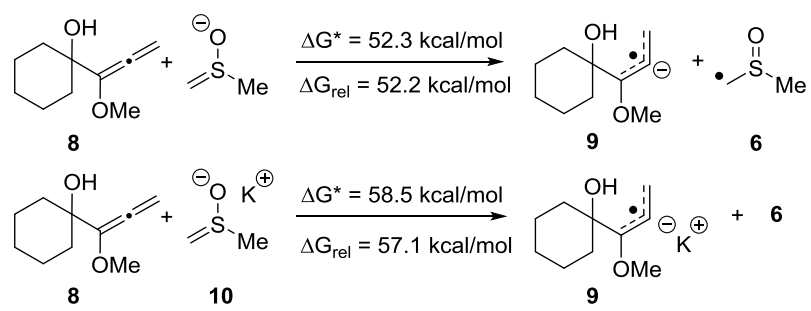

Scheme 2. Electron transfer from dimsyl anion and from dimsyl potassium 10 to model allene 8 in DMSO as solvent.

The energy profiles for the 5-endo-trig cyclizations of several alkoxide-allenes were optimized and the influence of the $\mathrm{R}^{1}$ and $R^{2}$ groups was investigated. (Schemes 3 and 4, Figure 1).

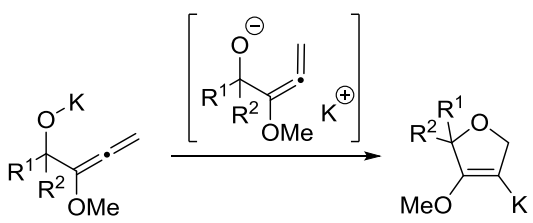

Scheme 3. Structures optimized for the cyclization of potassium alkoxideallenes to dihydrofuran derivatives.

Several potassium alkoxide-allenes were chosen, including the case where $R^{1}$ and $R^{2}$ are part of a cyclohexane ring (species 11); the energies of the optimized structures are represented in Figure 1. Optimization of the cyclization of anion 11, derived by deprotonation of $\mathbf{8}$, showed that the reaction energy barrier was achievable $\left(\Delta \mathrm{G}^{*}=27.5 \mathrm{kcal} / \mathrm{mol}\right)$, considering that these cyclizations usually occur upon heating. ${ }^{[3]}$ The reaction was endergonic $\left(\Delta \mathrm{G}_{\mathrm{rel}}=7.9 \mathrm{kcal} / \mathrm{mol}\right)$.

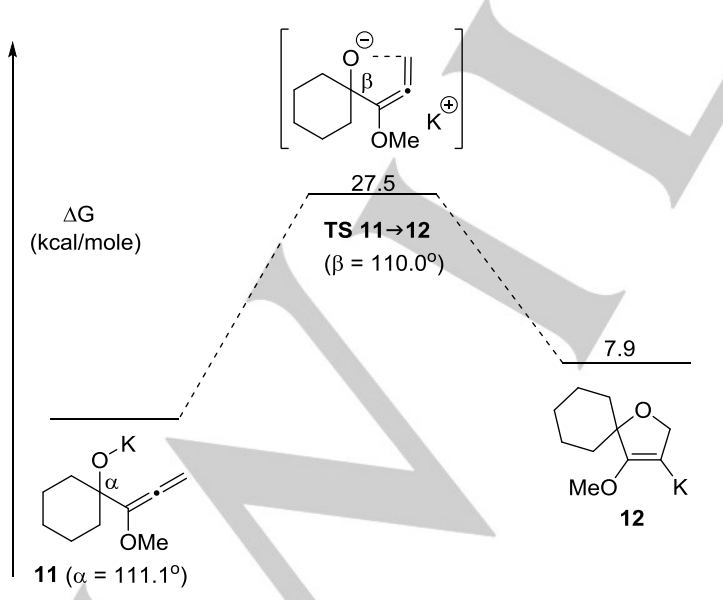

Figure 1. Free energy profile for cyclization of alkoxide-allene 11 to 12. Our calculations showed that the presence of the methoxy group led to a complexation to the potassium cation during optimization of the transition state and the cyclized product. This complexation between the oxygen of the methoxy group and the potassium was generally observed in our computational modelling; of course, complexation is also present in the starting materials e.g. 13 (Scheme 4). When the methoxy group was replaced by a methyl group, similar Gibbs free energies were observed. The energies required for cyclizations of a range of potassium alkoxide-allenes are of the same order of magnitude (Scheme 4). Increasing the size of $R^{1}$ and $R^{2}$ tends to decrease the energy barrier of the cyclization consistent with a ThorpeIngold effect, ${ }^{12}$ where both the angle $\alpha$ in the educt and $\beta$ in the TS are compressed (Figure 1 and Scheme 4).

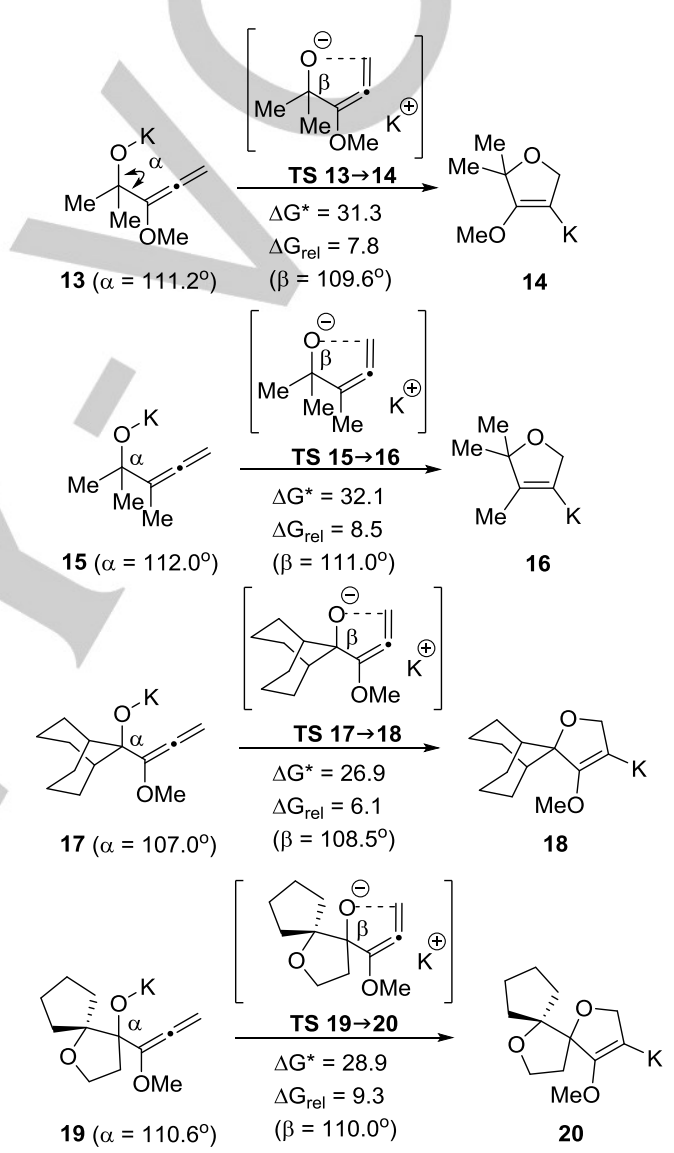

Scheme 4. Activation and relative free energies for the cyclization of potassium alkoxide-allenes (energies reported in $\mathrm{kcal} / \mathrm{mol}$ ).

An alternative cyclization could happen via a 4-exo-dig pathway. Such a cyclization was optimized from alkoxide allene 11 resulting in $\Delta G^{*}=26.9 \mathrm{kcal} / \mathrm{mol}$ and $\Delta G_{\text {rel }}=16.5 \mathrm{kcal} / \mathrm{mol}$ for product 21 (Scheme 5). These values show that the 4-exo-dig and the 5-endo-trig cyclization have similar T.S. energies, but they differ in the product stability. The formation of a strained four-membered ring is thermodynamically less favored compared to that of the five-membered ring, which is in accordance with the experimentally observed 5-endo-trig cyclization (cf. Figure 1 and Scheme 5).

Moving to the anionic cyclization of amide-allenes, the calculations were also made using potassium as a countercation and by modelling DMSO as solvent (Scheme 6). For 
these cyclizations, we chose the amide analogues of intermediate 8 and the influence of various $\mathrm{N}$-substituents was again investigated.

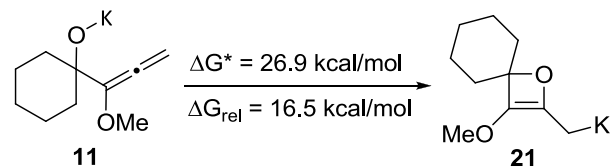

Scheme 5. 4-Exo-dig cyclization of 11 to oxetane derivative 21.

Two different cases quickly appeared: the energy barrier of the cyclization was $15.6-28.4 \mathrm{kcal} / \mathrm{mol}$, but the relative energies of products versus starting materials were quite different, depending on whether electron-donating or electron-attracting $\mathrm{N}$-substituents were present. The cyclizations were exergonic when an electron-donating alkyl substituent was present on the nitrogen atom; in contrast, the presence of an electronwithdrawing $\mathrm{N}$-substituent stabilized the initial amide anion as expected, leading to an endergonic reaction (Figure 2, Table 1). The difference from the cyclization of potassium alkoxide-allene is clear, as the nucleophilicity of the nitrogen can be easily modified by the electronic effect of its substituent.<smiles>[R]N([X])C1(C(=C)OC)CCCCC1</smiles>

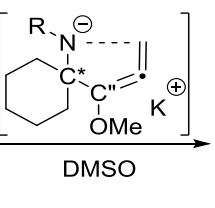

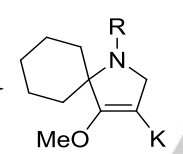

$\begin{array}{ll}\mathbf{2 2} & \mathrm{R}=\mathrm{Ts} \\ \mathbf{2 4} & \mathrm{R}=\mathrm{Ph} \\ \mathbf{2 6} & \mathrm{R}=\mathrm{Bn} \\ \mathbf{2 8} & \mathrm{R}=i \mathrm{Pr} \\ \mathbf{3 0} & \mathrm{R}=t \mathrm{Bu}\end{array}$

Scheme 6. Structures optimized for the cyclization of potassium amide-allenes

Table 1. Free energies of the cyclization of potassium amide-allenes in DMSO.

\begin{tabular}{|c|c|c|c|c|c|}
\hline Entry & Reactant & $\begin{array}{c}N \text {-Substituent } \\
\mathrm{R}\end{array}$ & Product & $\Delta G^{*[a]}$ & $\Delta \mathrm{G}_{\text {rel }}{ }^{[\mathrm{a}]}$ \\
\hline 1 & 22 & Ts & 23 & 28.4 & 13.1 \\
\hline 2 & 24 & $\mathrm{Ph}$ & 25 & 26.3 & 2.3 \\
\hline 3 & 26 & $\mathrm{Bn}$ & 27 & 15.6 & -19.7 \\
\hline 3 & 28 & $i \mathrm{Pr}$ & 29 & 21.4 & -19.4 \\
\hline 4 & 30 & $t \mathrm{Bu}$ & 31 & 21.1 & -16.5 \\
\hline
\end{tabular}

[a] Energies reported in $\mathrm{kcal} / \mathrm{mol}$.

The possibility of a 4-exo-dig cyclization was also investigated for 26 (leading to 32 as in Scheme 7) but, as observed with alkoxide allene 11 , the reaction $\left(\Delta \mathrm{G}^{*}=11.1 \mathrm{kcal} / \mathrm{mol}\right.$ and $\Delta \mathrm{G}_{\mathrm{rel}}=$
$-11.2 \mathrm{kcal} / \mathrm{mol}$, ) would be thermodynamically less favorable than the 5-endo-trig process (Figure 2).

Although the barrier is lower, the relative energy of the 4-exo-dig cyclization does not lead to as stabilized a product as the 5endo-trig cyclization.

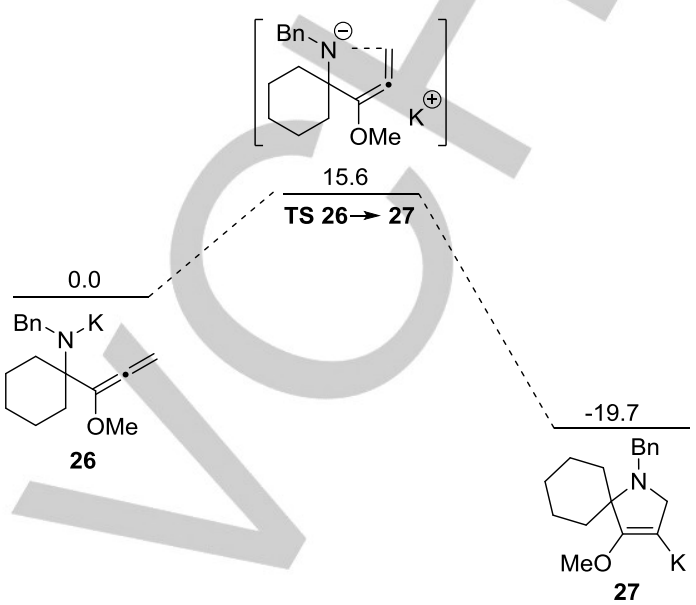

Figure 2 Free energy profile for cyclization of 26 (energies reported in $\mathrm{kcal} / \mathrm{mol})$.

The energy profiles of the 5-endo-trig cyclizations of amide allenes were also investigated as lithium salts in THF as solvent (Scheme 8, Table 2). For this paper, we treat the salts as monomeric. With both the potassium and lithium salts discussed here, we recognise that aggregation in solution may be important. 13 While the energies remain experimentally achievable, these cyclizations are more energy demanding than the cyclizations of the corresponding potassium salts in DMSO. The overall trend is clear and goes parallel to the observed experimental facts: ${ }^{[1]]}$ the reactions are exergonic with electronicdonating $\mathrm{N}$-substituents, whereas they are moderately endergonic with electron-withdrawing substituents.

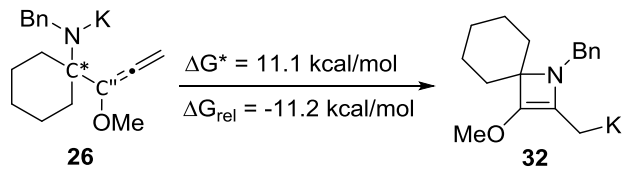

Scheme 7. 4-Exo-dig cyclization of $\mathbf{2 6}$ to azetidine derivative $\mathbf{3 2 .}$

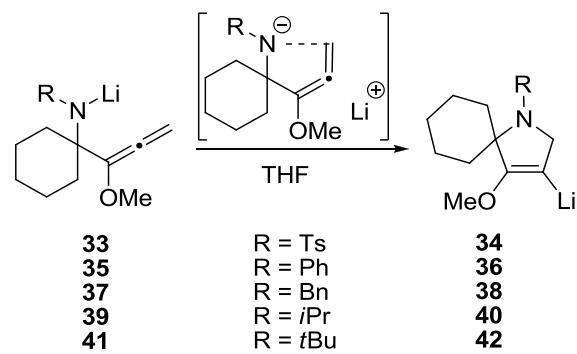

Scheme 8. Structures optimized for the cyclization of lithium amide-allenes

Table 2. Free energies of the cyclization of lithium amide-allenes in THF 


\begin{tabular}{llllll}
\hline Entry & Reactant & $\begin{array}{c}N \text {-Substituent } \\
\mathrm{R}\end{array}$ & Product & $\Delta \mathrm{G}^{*[a]}$ & $\Delta \mathrm{G}_{\mathrm{rel}}{ }^{[\mathrm{a}]}$ \\
\hline 1 & $\mathbf{3 3}$ & $\mathrm{Ts}$ & $\mathbf{3 4}$ & 30.9 & 6.1 \\
2 & $\mathbf{3 5}$ & $\mathrm{Ph}$ & $\mathbf{3 6}$ & 33.2 & -1.2 \\
3 & $\mathbf{3 7}$ & $\mathrm{Bn}$ & $\mathbf{3 8}$ & 28.4 & -19.3 \\
$\mathbf{4}$ & $\mathbf{3 9}$ & $\mathrm{iPr}$ & $\mathbf{4 0}$ & 24.9 & -26.1 \\
5 & $\mathbf{4 1}$ & $\mathrm{tBu}$ & $\mathbf{4 2}$ & 33.9 & -13.9 \\
\hline
\end{tabular}

[a] Energies reported in $\mathrm{kcal} / \mathrm{mol}$.

An electron transfer from the dimsyl anion to amine $\mathbf{4 3}$ was also optimized and showed once again that this electron transfer is very unlikely to happen $\left(\Delta \mathrm{G}^{*}=61.5 \mathrm{kcal} / \mathrm{mol}\right.$ and $\Delta \mathrm{G}_{\mathrm{rel}}=60.1$ $\mathrm{kcal} / \mathrm{mol}$, Scheme 9). The optimization of the electron transfer reaction with potassium salt $\mathbf{1 0}$ as electron donor was also made and here again, the energies involved would be too high to be experimentally achievable $\left(\Delta \mathrm{G}^{*}=70.8 \mathrm{kcal} / \mathrm{mol}\right.$ and $\Delta \mathrm{G}_{\mathrm{rel}}=64.9$ $\mathrm{kcal} / \mathrm{mol})$.

$$
\underbrace{\Theta_{10}}_{\mathrm{OMe}_{\mathrm{OMe}}}
$$

Scheme 9. Electron transfer from dimsyl anion and from dimsyl potassium 10 to amine-allene $\mathbf{4 3}$.

Overall, the obtained calculated data fit very well to the experimental observations. The reactions with higher calculated barriers proceed only slowly at higher temperatures, whereas the cyclizations with lower barriers occur under milder conditions (in part even in THF and with lithium as counter-ion). The barrier heights are affected by the degree of stabilisation of charge in the starting alkoxides or amides.

In summary, the cyclizations of alkoxide-allenes and amideallenes via an anionic process have been shown to be a feasible process, as the energies required can easily be achieved experimentally by heating the components. Products derived from 5-endo-trig cyclization are observed, rather than those from a 4-exo-dig pathway. The possibility for an electron transfer process to be the first step of the cyclization of these allenes is ruled out as having too unfavorable an activation energy. ${ }^{14}$

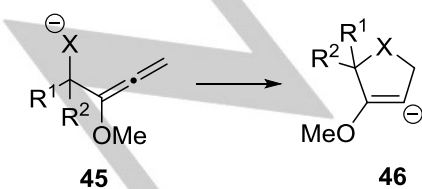

Scheme 10 Anionic cyclizations of allenes 45 to the carbanions 46 .

\section{Experimental Section}

All optimized structure coordinates are reported in the supporting information

\section{Acknowledgements}

We thank the University of Strathclyde and Deutsche Forschungsgemeinschaft for funding.

Keywords: alkoxyallenes $\cdot$ cyclizations $\cdot$ computation $•$ furans $•$ pyrroles

[1] Selected reviews: a) M. Brasholz, R. Zimmer, H.-U. Reissig, Acc. Chem Res. 2009, 42, 45-56. b) F. Pfrengle, H.-U. Reissig, Chem. Soc. Rev. 2010, 39, 549-557; c) A. Nedolya, O. Tarasova, O. G. Volostnykh, A. L. Albanov, L. V. Klyba, B. A. Trofimov, Synthesis 2011, 2192-2204; d) M. A. Tius, Chem. Soc. Rev. 2014, 43, 2979-3002; e) R. Zimmer, H.-U. Reissig, Chem. Soc. Rev. 2014, 43, 2888-2903; f) H.-U. Reissig, R. Zimmer, Synthesis, 2017, 49, 3291-3302.

[2] S. Hoff, L. Brandsma, J. F. Arens, Recl. Trav. Chim. Pays-Bas 1968, 87, 916-924.

[3] a) D. Gange, P. Magnus, J. Am. Chem. Soc. 1978, 100, 7746-7747; b) D. Gange, P. Magnus, L. Bass, E. V. Arnold, J. D. Clardy, J. Am. Chem. Soc. 1980, 102, 2134-2135; c) P. Magnus, P. Albaugh-Robertson, J. Chem. Soc. Commun. 1984, 804-806; c) S. Hormuth, H.-U. Reissig, J. Org. Chem. 1994, 59, 67-73; d) S. Hormuth, W. Schade, H.-U. Reissig, Liebigs Ann. 1996, 2001-2006; e) M. Brasholz, B. Dugovic, H.-U. Reissig, Synthesis, 2010, 3855-3864; f) for spontaneous cyclizations of allenyl alcohols and thiols to vinyl epoxides and thiiranes, see: $M$. Jasiński, G. Mlostoń, M. Stolarski, W. Costa, M. Dominguez, H.-U Reissig, Chem. Asian J. 2014, 9, 2641-2648

[4] a) J. E. Baldwin, J. Chem. Soc., Chem. Commun. 1976, 734-736; b) B Lam, R. P. Johnson, J. Am. Chem. Soc. 1983, 105, 7479; c) C. D. Johnson, Acc. Chem. Res. 1993, 26, 476-482; d) I. V. Alabugin, K. Gilmore, Chem. Commun. 2013, 49, 11246-11250; e) K. Gilmore, R. K. Mohamed, I. V. Alabugin, Comput. Mol. Sci. 2016, 6, 487-514. f) K. Gilmore, I. V. Alabugin, Chem. Rev. 2011, 111, 6513-6556. g) K. Gilmore, M. Manoharan, J. I-Chia Wu, P. v. R. Schleyer, I. V. Alabugin J. Am. Chem. Soc., 2012, 134, 10584-10594.

[5] Selected publications: a) A. D. Walsh, J. Chem. Soc. 1953, 2266-2288; b) R. Tonner, G. Frenking, Angew. Chem., Int. Ed. 2007, 46, 8695-8698; c) C. A. Dyker, V. Lavallo, B. Donnadieu, G. Bertrand, Angew. Chem., Int. Ed. 2008, 47, 3206-3209; d) D. S. Patel, P. V Bharatam, J. Org. Chem. 2011, 76, 2558-2567.

[6] a) M. O. Amombo, A. Hausherr, H.-U. Reissig, Synlett 1999, 1871-1874; b) O. Flögel, M. G. Okala Amombo, H.-U. Reissig, G. Zahn, I. Brüdgam, H. Hartl, Chem. Eur. J. 2003, 9, 1405-1415. c) O. Flögel, H.-U. Reissig, Synlett, 2004, 895-897; d) M. G. Okala Amombo, O. Flögel, S. Kord Daoroun Kalai, S. Schoder, U. Warzok, H.-U. Reissig, Eur. J. Org. Chem. 2017, 1965-1972. For related reactions with hydrazones followed by ring closure to 2,5-dihydropyrroles, see: e) V. Breuil-Desvergnes, J. Goré, Tetrahedron 2001, 57, 1939-1950. (h) V. Breuil-Desvergnes, J. Goré, Tetrahedron 2001, 57, 1951-1960.

[7] M. J. Frisch, G. W. Trucks, H. B. Schlegel, G. E. Scuseria, M. A. Robb, J. R. Cheeseman, G. Scalmani, V.Barone, B. Mennucci, G. A. Petersson, H. Nakatsuji, M. Caricato, X. Li, H. P. Hratchian, A. F. Izmaylov, J. Bloino, G. Zheng, J. L. Sonnenberg, M. Hada, M. Ehara, K. Toyota, R. Fukuda, J. Hasegawa, M. Ishida, T. Nakajima, Y. Honda, O. Kitao, H. Nakai, T. Vreven, J. A. Montgomery Jr, J. E. Peralta, F. Ogliaro, M. J. Bearpark, J. Heyd, E. N. Brothers, K. N. Kudin, V. N. Staroverov, R. Kobayashi, J. Normand, K. Raghavachari, A. P. Rendell, J. C. Burant, S. S. Iyengar, J. Tomasi, M. Cossi, N. Rega, N. J. Millam, 
M. Klene, J. E. Knox, J. B. Cross, V. Bakken, C. Adamo, J. Jaramillo, R Gomperts, R. E. Stratmann, O. Yazyev, A. J. Austin, R. Cammi, C Pomelli, J. W. Ochterski, R. L. Martin, K. Morokuma, V. G. Zakrzewski, G. A. Voth, P. Salvador, J. J. Dannenberg, S. Dapprich, A. D. Daniels, Ö. Farkas, J. B. Foresman, J. V. Ortiz, J. Cioslowski, D. J. Fox Gaussian 09, Revision D.01, Gaussian, Inc., Wallingford, CT, USA 2009.

[8] Y. Zhao, D. G. Truhlar, Acc. Chem. Res. 2008, 41, 157-167.

[9] V. A. Rassolov, M. A. Ratner, J. A. Pople, P. C. Redfern, L. A. Curtiss, J. Comput. Chem. 2001, 22, 976-984.

[10] a) V. Barone, M. Cossi, J. Phys. Chem. A 1998, 102, 1995-2001; b) M. Cossi, N. Rega, G. Scalmani, V. Barone, J. Comput. Chem. 2003, 24, 669-681.

[11] a) R. A. Marcus, J. Chem. Phys. 1965, 43, 679; b) S. F. Nelsen, S. C. Blackstock, Y. Kim, J. Am. Chem. Soc 1987, 109, 677-682.
[12] Y. Zheng, J. X. Xu, Progress in Chemistry, 2014, 26, 1471-1491; (b) N L. Allinger, V. Zalkow, J. Org. Chem., 1960, 25, 701-704; (c) R. M Beesley, C. K. Ingold, J. F. Thorpe, J. Chem. Soc., 1915, 107 1080-1106

[13] a) K. J. Msayib, C. I. F. Watt, Chem Soc. Rev. 1992, 21, 237-243; b) M. H. Chisholm, S. R. Drake, A. A. Naiini, W. E. Streib, Polyhedron 1991 10, 337-345.

[14] J. P. Barham, G. Coulthard, K. J. Emery, E. Doni, F. Cumine, G. Nocera, M. P. John, L. E. A. Berlouis, T. McGuire, T. Tuttle, J. A Murphy, J. Am. Chem. Soc. 2016, 138, 7402-7410. 


\section{Entry for the Table of Contents}

\section{COMMUNICATION}
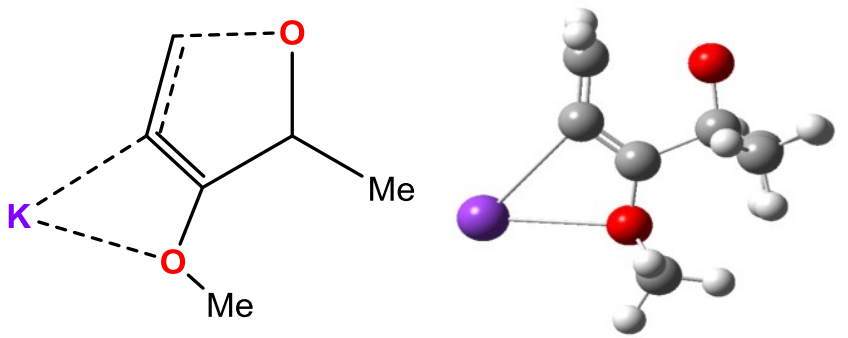

A computational study of anionic alkoxide-allene and amide-allene cyclizations

F. Cumine, A. Young, H.-U. Reissig, T. Tuttle, J. A. Murphy*

Page No. - Page No.

DFT computational studies support 5-endo-trig cyclization onto allenes

[a] F. Cumine, A. Young, Dr. T. Tuttle* and Prof. Dr. J._A. Murphy* Department of Pure and Applied Chemistry University of Strathclyde

295 Cathedral Street, Glasgow G1 1XL, United Kingdom

E-mail: t.tuttle@strath.ac.uk; john.murphy@strath.ac.uk

Freie Universität Berlin

Takustr. 3

14195 Berlin, Germany

Supporting information for this article is given via a link at the end of the document. 